\section{Long Helicenes by Alkyne Cycloisomerization}

Key words

helicenes

alkyne cycloisomerization

cobalt<smiles>C#Cc1cc(C#C)c(COCC#CC)cc1COCC#CC</smiles>

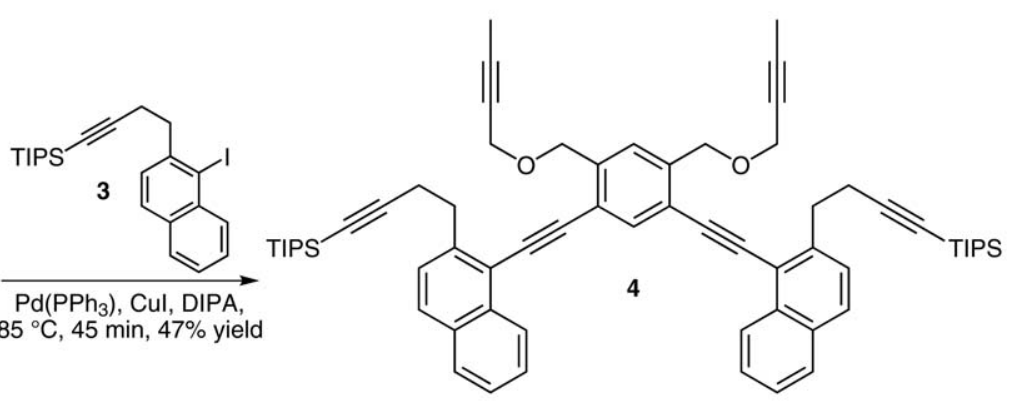
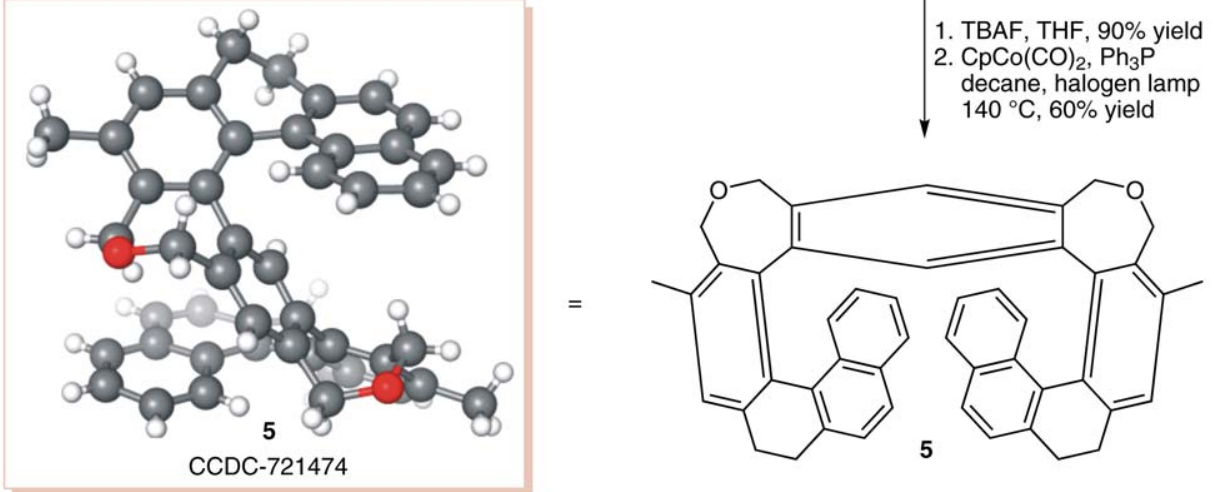

1. $\mathrm{CpCo}(\mathrm{CO})_{2}, \mathrm{Ph}_{3} \mathrm{P}$ decane, halogen lamp $140{ }^{\circ} \mathrm{C}, 40 \%$ yield

2. $\mathrm{TsOH} \cdot \mathrm{H}_{2} \mathrm{O}, \mathrm{C}_{6} \mathrm{H}_{6}, \mathrm{MW}$ $80^{\circ} \mathrm{C}, 30 \mathrm{~min}, 99 \%$ yield 3. $\mathrm{Ph}_{3} \mathrm{C}^{+} \mathrm{BF}_{4}^{-}, \mathrm{CH}_{2} \mathrm{Cl}_{2}$ $85{ }^{\circ} \mathrm{C}, 99 \%$ yield

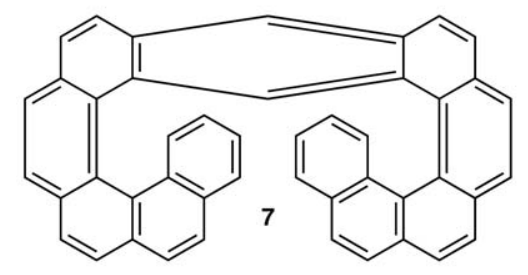

Significance: Helicenes have many possible applications in the areas of materials science, asymmetric catalysis, and molecular recognition; however, long helicenes represent challenging synthetic targets. Reported here is a synthetic route to undecacyclic helicenes utilizing a cobaltcatalyzed intramolecular [2+2+2] alkyne cycloisomerization. This key step forms six new rings of the helicene backbone in a single transformation.

SYNFACTS Contributors: Timothy M. Swager, David M. Chenoweth Synfacts 2009, 11, 1221-1221 Published online: 22.10.2009 Dol: 10.1055/s-0029-1218094; Reg-No.: S11709SF
Comment: Cobalt catalysts performed better than nickel catalysts for the cycloisomerization reaction with $\mathrm{CpCo}(\mathrm{CO})_{2} / \mathrm{Ph}_{3} \mathrm{P}$ giving higher yields than $\mathrm{CpCo}\left(\mathrm{C}_{2} \mathrm{H}_{4}\right)_{2}$ or $\mathrm{Ni}(\mathrm{cod})_{2}$. A slightly modified version of hexyne $\mathbf{4}$ underwent diastereoselective cyclization to afford a 10:90 ratio of products similar to $\mathbf{5}$ in 26\% yield. Racemic helicene $\mathbf{7}$ was purified by chiral HPLC and the racemization barrier at $230{ }^{\circ} \mathrm{C}$ was found to be $37.5 \mathrm{kcal} / \mathrm{mol}$. 